\title{
Application ofNanoparticlesby Layer-by-Layer (LBL) Deposition Technique to Improve the Functionality of Textiles
}

Dr. Chet Ram Meena

Department of Textile Design, National Institute of Fashion Technology, Jodhpur, Rajasthan, India

To Cite this Article

Dr. Chet Ram Meena, "Application ofNanoparticlesby Layer-by-Layer (LBL) Deposition Technique to Improve the Functionality of Textiles", International Journal for Modern Trends in Science and Technology, 6(9S): 183-191, 2020.

\section{Article Info}

Received on 25-August-2020, Revised on 08-September-2020, Accepted on 12-September-2020, Published on 18-September-2020.

\section{ABSTRACT}

Few decades back, a Nano word with big promising has been precipitously implying itself into the world's realization and associates with everyday life, economics and globally consequences. Functionalization of textile polymers has been practiced by different techniques to confer new properties on to the fibre so as to enable their application in fields other than textile industry. Nanotechnology may deliver the better performances and functionality to the textile materials due to the high surface area and energy. Further, Nanoparticles can apply on the fabrics by coating method without affecting the comfort and feel of the fabrics. It has improved the various properties like ultra violet protection, antibacterial and stain proof etc. LBL techniques is used to produce a thin polymeric film in a controlled manner on a surface of fabrics by using of different size of molecular weights and charges of polyelectrolytes. The unique feature of this technique is that it forms a very thin layer on fabric surface (1-10 nm) as compared to other available techniques; thus, no deterioration of surface properties of the substrate on which they are deposited. Nano $\mathrm{TiO}_{2}$ and $\mathrm{ZnO}$ particles along with polyelectrolytes and produce PEM on the Nylon 66 substrate by using LBL technique to get the antimicrobial and Ultraviolet protection property.

KEYWORDS:Antimicrobial Activity, Layer by layer technique, Nanoparticles, PEM, $\mathrm{TiO}_{2}$ and $\mathrm{ZnO} \mathrm{Nano}$ particles, Ultraviolet protection etc

\section{INTRODUCTION}

Different kinds of fibres are available now-a-days. These fibres are mainly divided into two categories natural and manmade. They are also categorized by the generations as they were produced in the different years and known as first generation, second generation, third generation or fourth generation fibres (1).

The name "nylons" refers to the group of plastics known as 'polyamides'. Nylons are typified by amide groups $(\mathrm{CONH})$ and encompass a range of material types (e.g. Nylon 6,6; Nylon 6,12; Nylon 4,6; Nylon 6; Nylon 12 etc.), providing an extremely broad range of available properties. Nylon is used in the production of film and fibre, but is also available as a moulding compound (2).

The nomenclature for describing the linear, aliphatic polyamides (the nylons) is based on the number of carbon atoms in the repeating unit. Both polyamide 6,6 and polyamide 6 have a high tensile strength but polyamide 6.6 is able to absorb water and whereas polyamide 6 has enhanced elasticity. Both are tough and have resistance to abrasion (3). 
The majority of nylons tend to be semi-crystalline and are generally very tough materials with good thermal and chemical resistance. The different types give a wide range of properties with specific gravity, melting point and moisture content tending to reduce as the nylon number increases.

\section{Need of Modification of Synthetic fibers}

The requirement of modification for a textile fibre is dependent on its characteristics and the end-use requirement. Textile finishes applied after the coloring process generally fall into one of two general categories according to purpose or end result. These categories are standard, wet or chemical finishes and decorative or mechanical finishes. Persons concerned with end products (designers, merchandisers and sales personnel) usually categoriesfinish as aesthetic finishes and functional finishes. The surface properties of the textile fibres govern the macroscopic properties of a textile such as hydrophilicity, adhesion property and optical appearance to a large degree. The former modifies the appearance and/or handle (feel) of fabrics, while the latter improve the performance of a fabric under specific end use conditions $(4,5)$.

\section{AFibres modification Methods}

In the last two decades, different means of modification of synthetic fibres have been thoroughly explored. The increasing expectancy for smart materials in daily life has of late sharply influenced research in the area of modification. Technologies that involve engineering to convert inexpensive materials into valuable finished goods have become more important in the present scenario (6).

The ideal modification that eliminates all the negative properties and preserves all positive properties of the fibres. In spite of the great number of existing modification methods no consistent classification is available as yet. The methods into two groups depending on whether they involve changes in fibre composition (chemical modification) or changes in fibre structure (physical modification). Development of processes for imparting these functionalities to the textile substrates is of prime importance $(7,8)$.

\section{Nanotechnology}

Over the past few years, a little word with big potential has been rapidly insinuating itself into the world's consciousness. That word is "nano." It has conjured up speculation about a seismic shift in almost every aspect of science and engineering with implications for ethics, economics, international relations, day-to-day life, and even humanity's conception of its place in the universe. As the possibilities of molecular nanotechnology grew and excitement built in the scientific community many researchers began using the term for their own endeavors at the nanoscale, unrelated to molecular manufacturing. Nanotechnology is the study and design of systems at the nanometer scale [0.000000001 (10-9) meter] the scale of atoms and molecules. Nanoscale materials can be rationally designed to exhibit novel and significantly improved physical, chemical and biological properties, because of their size (9).

\section{Polyelectrolytes}

Polyelectrolyte is defined as any polymeric substance in which the monomer units of its constituent's macromolecules hold ionisable groups. Electrochemically, a polyelectrolyte can be classified as either as polyacid, a polybase or a polyampholyte, depending upon the nature of ionization in aqueous solution.

The usual anionic polyelectrolytes are homo polymers and co polymers of $\mathrm{Na}$ Salt of acrylic acid with acrylamide.

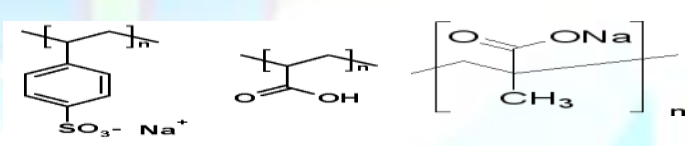

Figure 1: Poly (sodium 4-styrene sulfonate) (PSS) Poly (acrylic acid) (PAA) Poly (methacrylic acid sodium salt)

Cationic polyelectrolytes are photopolymers or copolymers with Acryl amide as major cationic monomer.

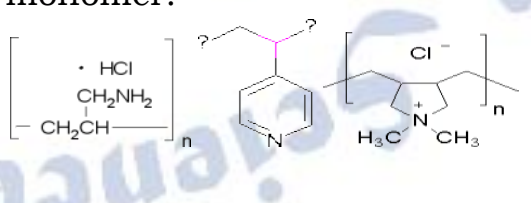

Figure 2: Poly (allyl amine hydrochloride) (PAH) Poly (diallyl dimethyl ammonium chloride) and Poly (4-vinylpyridine)

Nowadays polyelectrolytes are using in various industries like paper manufacturing, oil processing, treatment of water etc. Polyelectrolytes are responsible for the forms the thin polymeric 
film on the surface of textiles materials and offers the new innovations in unconventional textiles.

\section{ASEM photograph of PEM Film}

The polyelectrolyte LBL deposition technique has mainly been applied to deposit films onto planar surfaces or spheres. The progressive adsorption of

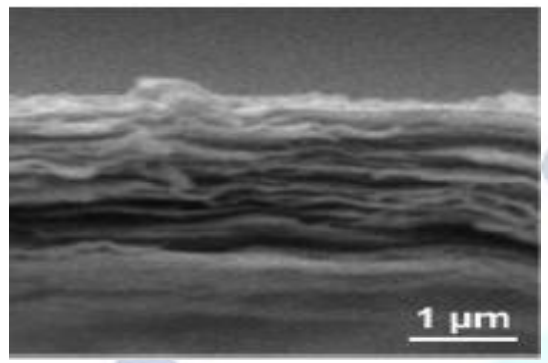

Figure 3: SEM photograph of PEM film

oppositely charged colloids and extended to the preparation of multilayers of polycations and phosphonate ions, as well as to the layering of polyelectrolytes.

The Electrostatic self-assembly (ESA) process is based on the alternating adsorption and self-organization of charged cationic and anionic species.
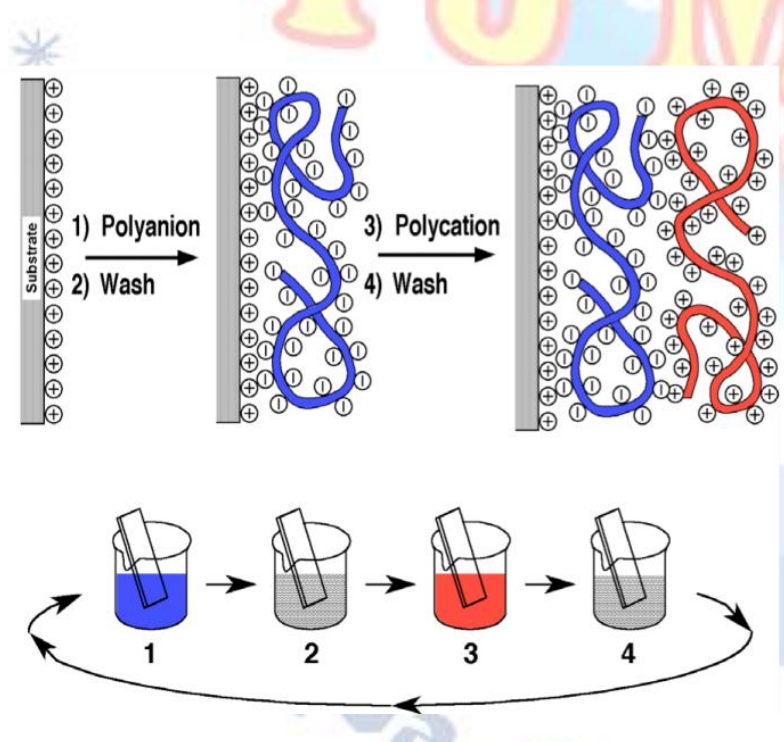

Figure 4: Simplified molecular picture of the first two adsorption steps, depicting film deposition starting with a negatively charged substrate.

Scheme of the LBL film-deposition process using glass slides and beakers. Steps 1 and 3 represent the adsorption of a polyanion and polycation, respectively, and steps 2 and 4 are washing steps (10).
LBL thin films can also be fabricated by exchanging charged species such as nanoparticles in place of or in addition to one of the polyelectrolytes.

LBL Technique is suitable for natural and synthetic fibres in form woven, knitted and nowoven structure. Significant features of LBL technique are, it can be used for optimized the performance by controlling the numbers of layers of PEM's. Other potential of PEMs in the various fields are Air Filter, Nanocapsules, Conducting Films for Solid State Electrolytes, Tubular Titania Nanostructures, Nanoelectromechanical systems (NEMS) \& micro-electromechanical systems (MEMS), Patterning of PEM etc. (11).

\section{Materials and Experiments Methods A Substrate and Chemicals}

Nylon 66 knitted fabric, GSM = 150 GSM (supplied by Piyush Trading, Mumbai).

Zinc Acetate dihydrate LR, Oxalic acid dihydrate, Ethanol Absolute AR (99.9\%), Hydrogen Peroxide, n-hexane, Sodium hydroxide and Nitric acid AR (1.42) were purchased from SD-fine chemicals Ltd, Mumbai. Ethandiol was procured from LobaChemie. Nano Zinc oxide was purchased from Sigma - Aldrich, Germany. Tetraisopropylorthotitanate (TIPT) was purchased from Merck, Germany. Flamcel P was supplied by BritacelPvt.1td. Mumbai. Fabshield AEM 5700 was supplied by Rossari Biotech Pvt. Ltd., Mumbai.Polyethylene Imine was supplied by BASF, Mumbai and Polyacrylic acid was sourced from Nixon Chemicals, Taloja, Navi Mumbai.

Nutrient Broth, M 002, Nutrient agar M 001 and Agar-agar, Type 1(all are Microbiology grade) were purchased from Himedia Lab. Ltd., Mumbai Staphylococcus Aureus (NCTC 3750 grade) and Escherichia Coli (AATCC-10148 grade) are obtained from Haffkins Research Institute, Parel, and Mumbai. All the cultures were maintained on Nutrient's agar medium by periodic sub culturing

\section{B Equipment's}

Surface morphology and elemental composition was characterized using SEM JEOL JSM 6380LA, JEOL 1td. Japan. XRD patterns were obtained by using Miniflex, Rigaku, Japan.The UPF value was determined with the help of Cary 100scan UV-Visible Spectrophotometer Varian EL0606308. Transmission electron Microscopic (TEM) and was used to characterize the nanoparticles composition, shape, size, Electron Diffraction 
Pattern and crystallinity by using TEM PHILIPS, Model: CM200S”. The synthesized $\mathrm{ZnO}, \mathrm{TiO} 2$ nanoparticles were analyzed for percentage moisture content by using moisture analyzer (Federal, India).

For antimicrobial testing following equipments were used Incubator cum Oven, Laminar air flow (Hexatec Instruments Pvt. Ltd., Mumbai, Model: HIPL-042), Colony Counter- Digital (LAPIZ), Autoclave Equitron (Sr.No. NC11GC-2824), and Water Bath cum Incubator (Rohini Fabricators).

\section{Synthesis of Nano Particles A Nano Titanium dioxide $\left(\mathrm{TiO}_{2}\right)$}

In this method, Tetraisopropylorthotitanate (TIPT) $2.84 \mathrm{ml}$ added in a solution of $0.5 \mathrm{ml}$ methanol and $5 \mathrm{ml}$ ethanol with molar ratio (1: $1: 10)$ and refluxed for 6 hour at $60^{\circ} \mathrm{C}$. Distilled water $(30 \mathrm{ml})$ added drop wise in above solution at $60^{\circ} \mathrm{C}$ under the continuous stirring condition. The precipitate isolated by filtration and washed 2-3 times with warm water. Precipitate dried at $130^{\circ} \mathrm{C}$ for 12 hour and then subjected to calcinations at $550^{\circ} \mathrm{C}$ for 10 hours in muffle furnace. The white crystalline powder of $\mathrm{Nano}^{\mathrm{TiO}}$ 2 was obtained at the end of the process (12).

\section{B Nano Zinc Oxide (ZnO)}

Synthesis of nano Zinc Oxide $(\mathrm{ZnO})$ are carried out by the using Zinc acetate dihydrate (10.98 gm) treated with ethanol $(300 \mathrm{ml})$ for $30 \mathrm{~min}$ at $60^{\circ} \mathrm{C}$. Oxalic acid dihydrate (12.6 gm) dissolved in ethanol $(200 \mathrm{ml})$ at $50^{\circ} \mathrm{C}$. The oxalic acid solution added slowly under the stirring conditions to the warm ethanolic solution of zinc acetate. A high viscous white gel formed, which is dried at $80^{\circ} \mathrm{C}$ for 20 hours and calcinations carried out in muffle furnace at $600^{\circ} \mathrm{C}$ for $2 \mathrm{hr}$ to yield $\mathrm{ZnO}$ nanoparticles (13).

\section{Characterization of Nano $\mathrm{ZnO}_{4} \mathrm{TiO}_{2}$}

\section{A. Moisture Content}

The synthesized nanoparticles were analyzed for percentage moisture content using moisture analyzer. The powder sample of 4-5 gm poured on the pan. Temperature ranges between $70^{\circ} \mathrm{C}-80^{\circ} \mathrm{C}$ given to the sample. After $4 \mathrm{~min}$ of elapsed time analyzer directly displayed percentage moisture present.

\section{B X-Ray diffraction (XRD)}

Wide angle XRD patterns were obtained using Miniflex, Rigaku, Japan with $\mathrm{Cu}$ Ka beam having wavelength $(\mathrm{X})=1.54 \AA$ used as the radiation source and Ni-filter. The diffractometer was operated at $30 \mathrm{KV}$ and $15 \mathrm{~mA}$ using a scanning step of 2 in two theta and a dwell time of 1 second was used. When X-rays fall on a sample, they get diffracted as per the Bragg's law;

depending upon the arrangement of atoms.

$\mathrm{n} \lambda=2 \mathrm{~d} \operatorname{Sin} \theta$

$\mathrm{X}$ - Wavelength of X-rays

$\mathrm{d}$ - Spacing between the two crystal layers

0 - Angle of incident of X-rays

$\mathrm{n}$ - Integer.

The sample was placed in a sample holder, and analysis was carried out in a static position and detector moving through input angle range.

\section{Transmission Electron Microscopic (TEM)}

Transmission electron Microscopic (TEM) is used to characterize the nanoparticles composition, their shape, size, electron diffraction pattern and crystallinity by using TEM PHILIPS, Model: CM200S". The specific surface area of the dry powders was also determined. TEM images are formed using transmitted electrons (instead of the visible light) which can produce magnification details up to $1,000,000 \mathrm{x}$ with resolution better than $10 \mathrm{~A}^{\circ}$. The images can be resolved over a fluorescent screen or a photographic film. Furthermore, the analysis of the X-ray produced by the interaction between the accelerated electrons with the sample allows determining the elemental composition of the sample with high spatial resolution.

\section{Scanning Electron Microscopic (SEM)}

Surface morphology was characterized using SEM JEOL JSM 6380LA, JEOL 1td. Japan. Scanning electron microscope is used to characterize the surface morphology showing nanoparticles bound to substrate.

\section{Preparation of PEM Formation}

Poly (ethylene imine) (PEI) (0.1 wt. \%) solution prepared by addition of $\mathrm{HNO}_{3}(1 \mathrm{M})$ to maintain the slightly acidic pH.Polyacrylic acid (PAA) (0.1 wt. \%) solution prepared the same way as PEI, to achieve the $\mathrm{pH}$ 5. Addition of $\mathrm{Nano} \mathrm{ZnO}$ and $\mathrm{TiO}_{2}$ to the PEI solution was always done just prior to beginning the self-assembly procedure.

Fabric strips should be fixed on sample holder in open condition. Dipping the fabric into a solution of 
positively charged polyelectrolyte (polyanion) results in adsorption of first layer. A washing step is needed to remove unfixed particles. Now the surface potential is positive and a polyanion is adsorbed and thus one bilayer is formed. Subsequently again, a washing step is required in the end. The initial layer for each fabric strip was deposited by dipping the fabric into each of the ionic solutions for $2 \mathrm{~min}$, beginning with the cationic solution. Subsequent layers were also deposited with $2 \mathrm{~min}$ dips. Each dip was followed by rinsing with normal water for a 2 min. Succeeding the deposition of required number of layers, fabric strips were dried in air to remove remaining water.

\section{Antimicrobial Activity}

The functionalization of textile polymers can be achieved by using LBL technique by adding the active component such as Nano particles into one of the polyelectrolyte solution. Nylon being an amphoteric fibre has both carboxyl and amine end groups. PEI and PAA are used and they have amine and acidic group respectively in its structure, is capable of forming ionic bonds with Nylon as well as with each other. Therefore, PEM that is built onto the Nylon is strongly bonded with the fabric. AATCC 100-2004 method is used to evaluate the antibacterial activity of the treated samples.

\section{Ultraviolet Protection Factor (UPF)}

The Ultraviolet Protection Factor (UPF) or Sun Protection Factor (SPF) terms are commonly used as a measuring unit for Ultraviolet radiation. Spectrophotometer was used to measure the percent transmission at wavelength intervals upto $5 \mathrm{~nm}$ in the $290-400 \mathrm{NM}$ spectral span. The UPF is examined by the following equation.

$$
\mathrm{UPF}=\frac{\sum_{280 \mathrm{~mm}}^{400 \mathrm{~mm}} E_{i} S_{i} \Delta_{i}}{\sum_{280 \mathrm{~mm}}^{4(0) \mathrm{mm}} E_{j} S_{i} T_{i} \Delta_{i}}
$$

where

$E(\lambda)$ is the spectral weighting function of erythemal action spectra,

$S(\lambda)$ spectral irradiation for appropriate solar radiation spectrum $(W \mathrm{~m}-2 \mathrm{~nm}-1)$,

$\tau(\lambda)$ spectral transmittance through specimen, and

$(\Delta)$ appropriate wavelength measuring interval (nm) (14).

\section{RESULTS \& DISCUSSIONS}

\section{A. Antimicrobial Activity against Nano $\mathrm{TiO}_{2}$}

Nano $\mathrm{TiO}_{2}$ particles are added into the PEI solution so that it gets entrapped into the PEM as the number of layers is built up onto the Nylon Fabric.

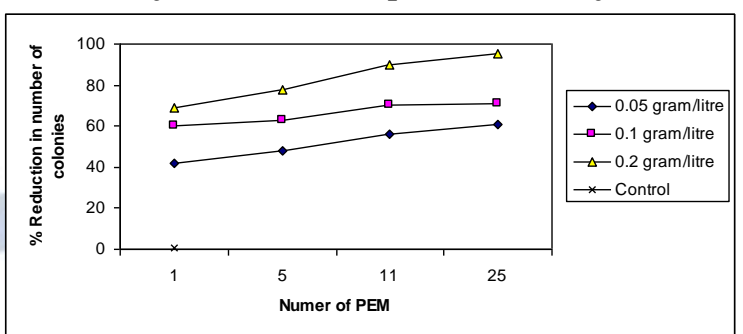

Figure 5: Relation between different amount of synthesized $\mathrm{TiO}_{2}$ and layers of PEM on \% Reduction in number of $S$. Aureus colonies on Nylon Fabric

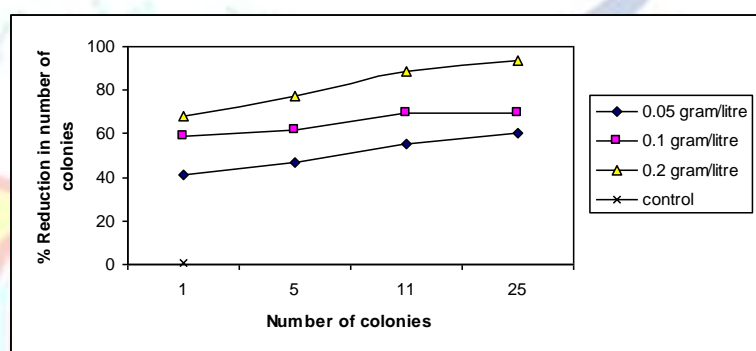

Figure 6: Relation between different amount of synthesized $\mathrm{TiO}_{2}$ and Layers of PEM on \%

Reduction in number of $E$. coli colonies on Nylon Fabric.

As shown in figure $5 \& 6$ that results of antimicrobial activity on Nylon Fabric V/s Number of layers deposited and amount of nano $\mathrm{TiO}_{2}$. The $\%$ reduction in number of colonies of $S$. Aureus and E. coli for $\mathrm{TiO}_{2}$ increases from 1 st to 25 th PEM. As the concentration of $\mathrm{TiO}_{2}$ is increased from 0.05 , 0.1 to 0.2 gram/liter, the \% reduction in number of colonies increases from $61 \%$ to $71 \%$ to $95 \%$ respectively for the 25 th layer.

Thus, if we increase the concentration of nano $\mathrm{TiO}_{2}$ in the polyelectrolyte solution the required effect can be obtained at less number of layers thereby saving time and chemicals. Further, also as the number PEM goes on increasing from 1 st to 25 th PEM there is an additional improvement in antimicrobial activity because as number of layers are built up, there is a proportionate increase in the concentration of $\mathrm{TiO}_{2}$ onto the fabric.

The washing durability of nano $\mathrm{TiO}_{2}$ treated fabric as shown in Table 3. It can be noticed that there is a negligible drop in antimicrobial activity from $69 \%$ to $64.5 \%$ for 1 st layer and from $95 \%$ to $93.5 \%$ for 
25th layer. Results verifies that nano $\mathrm{TiO}_{2}$ particles deposited on the fabric are strongly bonded to the fabric. It is clear that synthesized nano $\mathrm{TiO}_{2}$ either before and after washing shows more or less similar antimicrobial property.

Table 3: Effect of washing treatment on synthesized Nano $\mathrm{TiO}_{2}$ and Number of PEM on antimicrobial activity of Nylon Fabric for $S$.

\section{Aureus}

\begin{tabular}{|c|c|c|c|c|c|c|}
\hline \multirow{4}{*}{$\begin{array}{l}\text { Number } \\
\text { of } \\
\text { Layers }\end{array}$} & \multicolumn{6}{|c|}{ Amount of nano $\mathrm{TiO}_{2}, 0.2$ gram/liter } \\
\hline & \multicolumn{3}{|c|}{ Before wash } & \multicolumn{3}{|c|}{ After wash } \\
\hline & \multicolumn{2}{|c|}{$\begin{array}{l}\text { Number of } \\
\text { Colonies } \\
\text { after }\end{array}$} & \multirow{2}{*}{$\begin{array}{l}\% \\
\text { Reductio } \\
\mathrm{n} \text { in } \\
\text { Number } \\
\text { of } \\
\text { Colonies }\end{array}$} & \multicolumn{2}{|c|}{$\begin{array}{l}\text { Number of } \\
\text { Colonies } \\
\text { after }\end{array}$} & \multirow{2}{*}{$\begin{array}{l}\text { \% } \\
\text { Reductio } \\
\mathrm{n} \text { in } \\
\text { Number } \\
\text { of } \\
\text { Colonies }\end{array}$} \\
\hline & $\begin{array}{l}\begin{array}{l}0 \\
\text { hou } \\
\mathrm{r}\end{array} \\
\end{array}$ & $\begin{array}{l}24 \\
\text { hou } \\
\text { r }\end{array}$ & & $\begin{array}{l}0 \\
\text { hou } \\
\mathrm{r}\end{array}$ & $\begin{array}{l}24 \\
\text { hou } \\
\text { r }\end{array}$ & \\
\hline $\begin{array}{l}\text { \#Contro } \\
1\end{array}$ & 786 & 780 & 0.76 & 786 & 780 & 0.76 \\
\hline 1 & 99 & 31 & 69 & 105 & 38 & 64.5 \\
\hline 5 & 72 & 16 & 78 & 79 & 19 & 76 \\
\hline 11 & 55 & 6 & 90 & 61 & 8 & 88 \\
\hline 25 & 17 & 1 & 95 & 23 & 2 & 93.5 \\
\hline
\end{tabular}

\# Control $=$ Nylon fabric treated with only PEM (up to 25 layers)

\section{B Antimicrobial Activity against Nano ZnO}

The treated fabric shows antimicrobial activity is because of the presence of nanoZnO on the fabric which is a very efficient antimicrobial compound. Also as the number layers goes on increasing from 1 to 25 there is further improvement in antimicrobial activity because as number of layers are built up, there is a proportionate increase in the concentration of $\mathrm{ZnO}$ on the fabric.

Also as the concentration of $\mathrm{ZnO}$ added into the PEI solution when increased from 0.05 to 0.1 to 0.2 gram/litre the amount of nanoZnO that gets deposited onto the fabric increases and this results in the enhanced antimicrobial activity for the same number of layer but having different concentration.

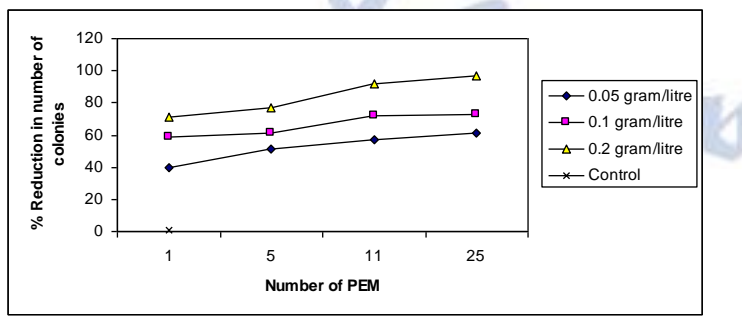

Figure 7: Relation between amount of synthesized $\mathrm{ZnO}$ and layers of PEM on \% Reduction in number of $\mathbf{S}$. Aureus colonies on Nylon Fabric
Here also the \% reduction in number colonies increased from $39 \%$ for the 1 st layer to $62 \%$ for the 25th layer for 0.05 gram/liter concentration of Nano $\mathrm{ZnO}$ for S. Aureus and from $38 \%$ to $61 \%$ for $E$. coli. The antimicrobial activity showed an improvement upto $96 \%$ for S. Aureus and $94.5 \%$ for $E$. coli when the concentration of $\mathrm{ZnO}$ is increased to 0.2 gram/litre when one considers the 25 th layer as shown in Figure $7 \& 8$.

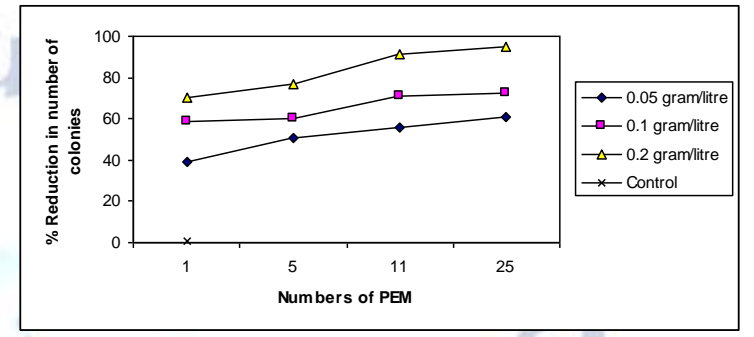

Figure 8: Relation between amount of synthesized ZnO and layers of PEM on \% Reduction in number of E.coli colonies on Nylon Fabric

\section{Comparison between synthesized Nano ZnO and Fabshield AEM 5700 (Aldrich-sigma) for Antimicrobial Activity}

Fabshield AEM 5700 (Aldrich-sigma), a commercial antimicrobial sample based on silver is also tested for the comparison, using of 0.05 gram/liter concentration to assess the efficacy of synthesized nanoZnO particles for S. Aureus as shown in Table 4.

The $\%$ reduction in number of number of colonies was $39.5 \%$ and $56 \%$ for synthesized $\mathrm{ZnO}$ and Fabshield AEM 5700, respectively for 1st layer. The correspondingly value were $61.5 \% 96 \%$ for 25 th layer. These values indicate that 0.05 gram/litre concentration of nano $\mathrm{ZnO}$ is not sufficient to get the comparable results with the Fabshield but 0.2 gram/litre concentration is to be used for which the values are $96.5 \%$ and $96 \%$. 
Table 4: Effect of synthesized Nano ZnO\&Fabshield AEM 5700 and Number of PEM on antimicrobial activity of Nylon Fabric for $\mathbf{S}$. Aureus

\begin{tabular}{|c|c|c|c|c|c|c|}
\hline \multirow{4}{*}{$\begin{array}{l}\text { Numb } \\
\text { er of } \\
\text { Layers }\end{array}$} & \multicolumn{6}{|c|}{$\begin{array}{l}\text { Concentration of nanoZnO and Fabshield } \\
\text { AEM } 5700,0.05 \text { gram/liter }\end{array}$} \\
\hline & \multicolumn{3}{|c|}{ Nano $\mathrm{ZnO}$} & \multicolumn{3}{|c|}{$\begin{array}{l}\text { Fabshield AEM } \\
5700\end{array}$} \\
\hline & \multicolumn{2}{|c|}{$\begin{array}{l}\text { Number } \\
\text { of } \\
\text { Colonies } \\
\text { after }\end{array}$} & \multirow{2}{*}{$\begin{array}{l}\% \\
\text { Reducti } \\
\text { on in } \\
\text { Numbe } \\
r \quad \text { of } \\
\text { Colonie } \\
\text { s }\end{array}$} & \multicolumn{2}{|c|}{$\begin{array}{l}\text { Number } \\
\text { of } \\
\text { Colonies } \\
\text { after }\end{array}$} & \multirow{2}{*}{$\begin{array}{l}\% \\
\text { Reducti } \\
\text { on in } \\
\text { Numbe } \\
\mathrm{r} \text { of } \\
\text { Colonie } \\
\mathrm{s}\end{array}$} \\
\hline & $\begin{array}{l}\text { O } \\
\text { ho } \\
\text { ur }\end{array}$ & $\begin{array}{l}24 \\
\text { ho } \\
\text { ur }\end{array}$ & & $\begin{array}{l}\text { O } \\
\text { ho } \\
\text { ur }\end{array}$ & $\begin{array}{l}24 \\
\text { ho } \\
\text { ur }\end{array}$ & \\
\hline $\begin{array}{l}\text { \#Cont } \\
\text { rol }\end{array}$ & $\begin{array}{l}78 \\
6\end{array}$ & $\begin{array}{l}78 \\
0\end{array}$ & 0.76 & $\begin{array}{l}78 \\
6\end{array}$ & $\begin{array}{l}78 \\
0\end{array}$ & 0.76 \\
\hline 1 & $\begin{array}{l}15 \\
8\end{array}$ & 96 & 39.5 & 90 & 40 & 56 \\
\hline 5 & $\begin{array}{l}14 \\
5\end{array}$ & 72 & 51 & 62 & 21 & 67 \\
\hline 11 & 98 & 43 & 57 & 33 & 8 & 78 \\
\hline 25 & 81 & 32 & 61.5 & 21 & 1 & 96 \\
\hline
\end{tabular}

\section{Ultraviolet Protection against Nano ZnO}

The ultra violet protection of treated Fabric $\mathrm{V} / \mathrm{s}$ Number of layers deposited and concentration of synthesized Nano $\mathrm{ZnO}$ and commercial Nano $\mathrm{ZnO}$ as shown in Table No 5 . UPF of treated fabric goes on progressively increasing from $167 \mathrm{~nm}$ for $1 \mathrm{st}$ Layer to $271 \mathrm{~nm}$ for 25th layer when the concentration of Nano $\mathrm{ZnO}$ in the solution is 0.05 gram/liter.

It is also observed that as the concentration of $\mathrm{ZnO}$ is increased from 0.05 gram/Litre to 0.2 gram/liter the ultra violet protection factor of Nylon Fabric

$295 \mathrm{~nm}$ for 0.1 gram/liter and upto $325 \mathrm{~nm}$ for 0.2 gram/liter with the number of layers being 25th for all the three concentration. This fact is further enhanced further from $271 \mathrm{~nm}$ for 0.05 gram/Litre to underline by the fact that in case of 0.2 gram/liter of concentration for the first layer itself, the ultra violet protection factor $235 \mathrm{~nm}$ is almost equal to that of 25th layer of 0.05 gram/liter concentration $271 \mathrm{~nm}$. Thus, as the concentration of Nano particles in the polyelectrolyte solution is increased the desired effect can be achieved at less number of layers thereby saving the time and chemicals.

Table 5: Effect of Concentration of nano synthesized ZnO, Aldrich -sigma \& Washing treatment and Number of PEM on Ultra Violet Protection Factor of Nylon Fabric

\begin{tabular}{|c|c|c|c|c|}
\hline \multirow[b]{2}{*}{$\begin{array}{l}\text { Concen } \\
\text { tration } \\
\text { of } \\
\text { nanoZn } \\
\text { O, gpl }\end{array}$} & \multirow[b]{2}{*}{$\begin{array}{l}\text { No. } \\
\text { of } \\
\text { Laye } \\
\text { rs }\end{array}$} & \multicolumn{3}{|l|}{ UPF (nm) } \\
\hline & & $\begin{array}{l}\text { Synthesized } \\
(\mathrm{ZnO})\end{array}$ & $\begin{array}{l}\text { Aldri } \\
\text { ch-si } \\
\text { gma } \\
- \text { Zn } \\
\text { O }\end{array}$ & $\begin{array}{l}\text { After } \\
\text { one } \\
\text { wash }\end{array}$ \\
\hline \multicolumn{2}{|l|}{$\begin{array}{l}\text { Untreat } \\
\text { ed } \\
\text { (Nylon } \\
\text { Fabric) }\end{array}$} & \multicolumn{3}{|l|}{74} \\
\hline $\begin{array}{l}\text { Control } \\
\text { (Nylon } \\
\text { fabric } \\
\text { treated } \\
\text { with } \\
\text { only } \\
\text { PEM } \\
\text { (up to } \\
25 \\
\text { layers) }\end{array}$ & & 75 & \multicolumn{2}{|c|}{$\underset{B}{\infty}$} \\
\hline \multirow{4}{*}{0.05} & 1 & 167 & 185 & 164 \\
\hline & 5 & 225 & 221 & 219 \\
\hline & 11 & 244 & 243 & 236 \\
\hline & 25 & 271 & 268 & 256 \\
\hline \multirow{4}{*}{0.1} & 1 & 226 & 224 & 215 \\
\hline & 5 & 231 & 228 & 222 \\
\hline & 11 & 235 & 241 & 227 \\
\hline & 25 & 295 & 289 & 277 \\
\hline \multirow{4}{*}{0.2} & 1 & 235 & 232 & 225 \\
\hline & 5 & 259 & 255 & 244 \\
\hline & 11 & 298 & 297 & 282 \\
\hline & 25 & 325 & 319 & 306 \\
\hline
\end{tabular}

The comparative study of UPF of the Nano $\mathrm{ZnO}$ obtained from Sigma Aldrich with that of synthesized Nano ZnO synthesized as shown in Table 5. Here again the same trend in results is observed for nanoZnO particles from Aldrich- 
sigma were used. For 1st layer, when concentration is 0.05 gram/litre the UPF values are $167 \mathrm{~nm}$, and $185 \mathrm{~nm}$ respectively for synthesized $\mathrm{ZnO}$ and $\mathrm{ZnO}$ obtained from Aldrich-sigma. For the 25th layer and same concentration the values are $271 \mathrm{~nm}$ and $268 \mathrm{~nm}$. Similar behavior is observed for the other two concentrations. Thus, the synthesized nanoparticles are equivalent to the commercial nanoZnO particles.

It would be worthwhile to see whether the nano particles deposited via LBL technique are resistant to washing treatment. To assess this, Nylon fabric activated by synthesized nanoZnO particles, were subjected to one washing cycle and then again evaluated for their UPF. Presented in the Table 5. it can be seen that UPF has marginally dropped due to washing effect. It is $167 \mathrm{~nm}$ for unwashed sample, $164 \mathrm{~nm}$ after first washing cycle for 1 st layer for 0.05 gram/litre concentration. For the same concentration, the values for 25 th layer are, $271 \mathrm{~nm}$ for unwashed sample and $256 \mathrm{~nm}$ for washed sample. Thus, the UPF did not deteriorate too much after washing. The only possible reason for this is the ability nano $\mathrm{ZnO}$ particles to hold on to the fabric even during washing. The SEM pictures of unwashed and washed Nylon fabric are shown in Figure 9. We can see the presence of Nano particles on the washed samples and this is the reason why even after washing; nano particles are firmly bound to the fabric and hence show UPF property.

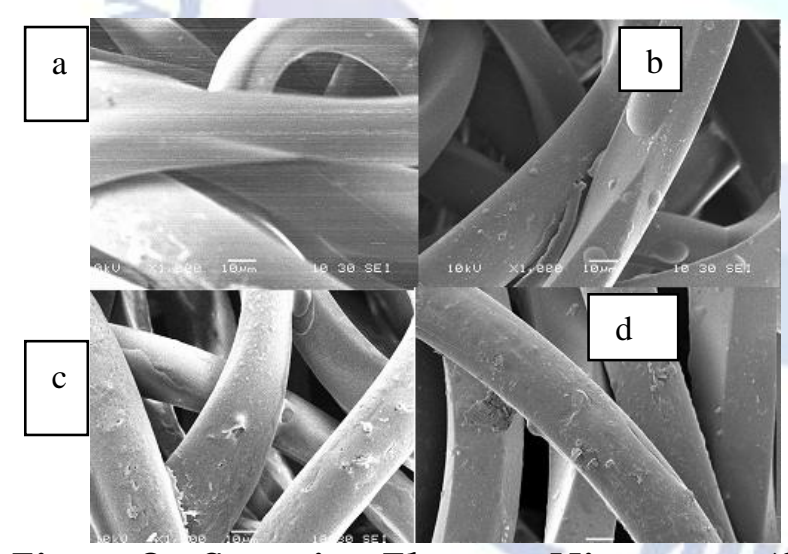

Figure 9: Scanning Electron Microscope (SEM) image of nylon surface (a) untreated (b) Nano ZnO (c) Aldrich -Sigma (d) Nano ZnO (after washing)

\section{E Ultraviolet Protection against Nano $\mathrm{TiO}_{2}$}

The UPF value for $\mathrm{NanoTiO}_{2}$ increases from $198 \mathrm{~nm}$ for 1st layer to $298 \mathrm{~nm}$ for 25th layer for 0.05 gram/litre concentration. It has clear from table
No. 6 that the concentration of $\mathrm{TiO}_{2}$ is increased from $0.05,0.1$ and 0.2 gram/liter the UPF increases from $298 \mathrm{~nm}$ to $311 \mathrm{~nm}$ to $391 \mathrm{~nm}$ respectively for the 25th layer.

The washing fastness of $\mathrm{TiO}_{2}$ deposited on nylon for single washing cycle is assessed. The UPF is $198 \mathrm{~nm}$ and $188 \mathrm{~nm}$ for unwashed and washed sample respectively for concentration 0.05 gram/litre. The values for 25th layer is $298 \mathrm{~nm}$ and $278 \mathrm{~nm}$ for the same concentration. Thus, the UPF decreased after single washing but to a lower extent because some of the nano particles gets washed.

Table 6: Effect of different concentration of nano $\mathrm{TiO}_{2}$, washing treatment and Number of PEM on Ultra Violet Protection Factor of Nylon Fabric

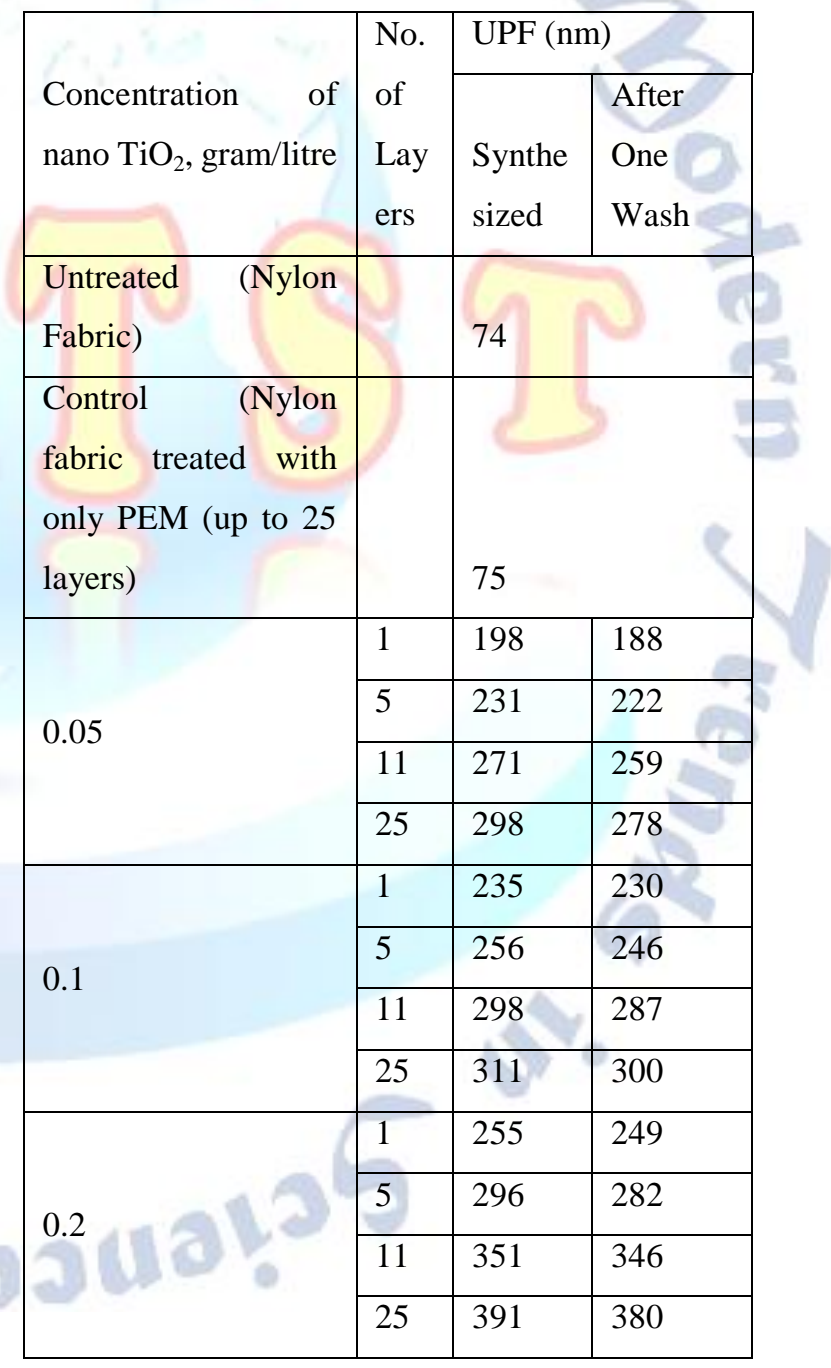

\section{CONCLUSION}

Worldwide nanoparticles have the potential market. It has numerous areas to improve the performance of textiles and other materials. The most challenging area is application techniques of Nanoparticles on textiles and to get the optimized results. There are few conventional 
methods/techniques for application of nanoparticles by exhaust, padding, coating etc. One of the unconventional technique is LBL techniques. It has additional significant benefits are controlled and effective over the conventional techniques and allows more versatility on different surfaces. Polyelectrolytes are the basic composition along with functional elements for LBL techniques. LBL technique may be used on textiles, optical, magnetic, chemical, electrical etc. The functionality of the treated fabric has increased with increase the quantity of $\mathrm{TiO}_{2}$ and $\mathrm{ZnO}$ Nano particles and the number of layers. Therefore, higher quantity of nanoparticles can improve the antimicrobial property \& UPF property of treated fabric with less number of PEMs. The effectiveness of the antimicrobial activity and UPF is comparable with the commercial available nano particles/products in market.

\section{REFERENCES}

1. Vaidya AA, Production of Synthetic Fibres, ed.1, 1986, pp 1-10, 280-285.

2. https://www.bpf.co.uk/plastipedia/polymers/polyamides .aspx

3. https://www.essentialchemicalindustry.org/polymers/pol yamides.html

4. P. Bajaj Indian Journal of Fibre\& Textile research, 26(2),2001 pp 162-186.

5. Knittel D., Schollmeyer E., Journal of Textile Institute, 3, 2000, pp 151-165.

6. Desai Shrojal M, Singh. R.P., Journal-Advances in polymer science, 169, 2004, pp 231-293.

7. Shenai V.A., Textile Fibers, 1, 1994, pp 11-15.

8. http://www.thenonwovensinstitute.com/ncrc/acrobatfiles /Thesis/Fiber\%20Surface $\% 20$ Modification $\% 20$ by $\% 20$ Parti cle\%20Coating.pdf

9. M. Ratner \& D. Ratner, Nanotechnology: A Gentle Introduction to the Next Big Idea, Prentice Hall PTR, New Jersey, 2002, pp 7-8, 10-12, 35-39, 40-41.

10. G. Decher, Science 277, 1232-1237, 1997.

11. R.D. Kale \& Chet Ram Meena, International Dyer, pp 26-29. November 2008.

12. R. D. Kale and Chet Ram Meena, Advances in Applied Science Research, Vol. 3 (5), pp 3073-3080, 2012.

13. R. D. Kale and Chet Ram Meena, International Journal of Basic and Applied Chemical Sciences, Vol. 1 (1), pp1-8, 2011.

14. Shalini G, Anitha D, International Journal of Science and Research (IJSR), Volume 5 Issue 10, pp766-768, October 2016. 